\title{
A potencialidade das tecnologias, no ensino básico
}

\author{
Teresa Jesus Correia Paulino-Santos \\ Agrupamento de Escolas Gil Vicente - Portugal
}

\begin{abstract}
Resumo
As Tecnologias da Informação e da Comunicação (TIC) em Portugal, assumem uma importante dimensão pedagógica em toda a escolaridade obrigatória, de forma diversificada. Elas potenciam a organização, a planificação das atividades e são integradas no currículo escolar como uma forma de renovação das oportunidades de aprendizagem. Para isso contribuíu a generalização da utilização dos computadores, o acesso às redes eletrónicas de informação e os recursos disponiveis na Web por alunos e professores. Através deste estudo pretende-se identificar e contextualizar a utilização das TIC nos alunos do $2^{\circ}$ e $3^{\circ}$ ciclos do ensino básico como recurso didático para o desenvolvimento de competências transversais .
\end{abstract}

\section{Introdução}

O desenvolvimento tecnológico das últimas décadas originou avanços extraordinários em praticamente todas as áreas do conhecimento, facto que não esteve alheia a educação. No contexto da educação, a escola surge como um espaço privilegiado de interação social, integrado nos demais espaços de conhecimento que incorporam a informação, a matéria-prima e as tecnologias agir sobre a informação (Castells,2005), pois permite fazer as pontes entre conhecimentos tornar-se num novo elemento de cooperação e transformação.

Estas novas formas de comunicar e trabalhar, requerem de dispositivos de formação e certificação de competências básicas em TIC, como o pensamento crítico, a gestão do conhecimento, o aprender a aprender, entre outras. Em Portugal foi implementado, em 2007, o Plano Tecnológico da Educação (PTE, 2007), tendo como ambição colocar Portugal entre os cinco países europeus mais avançados em matéria de modernização tecnológica das escolas até 2010. Com um período de implementação previsto de três anos (2007-2010) e estruturado em três grandes eixos - Tecnologia, Conteúdos e Formação - pretendia abarcar na globalidade ou em parte, todas as áreas relacionadas com a modernização da escola portuguesa. Este plano ambicioso propunha atingir os seguintes objetivos até 2010: Atingir a rácio de dois alunos por computador com ligação à Internet; Garantir em todas as escolas o acesso à Internet em banda larga de alta velocidade de pelo menos 48 Mbps; Assegurar que, em 2010, docentes e alunos utilizam TIC em pelo menos 25\% das aulas; Massificar a utilização de meios de comunicação electrónicos, disponibilizando endereços de correio electrónico a 100\% de alunos e docentes já em 2010; Assegurar que, em 2010, 90\% dos docentes veem as suas competências TIC certificadas; Certificar $50 \%$ dos alunos em TIC até 2010.

Houve um esforço significativo em equipar e renovar o parque informático e equipamentos multimédia das escolas portuguesas, bem como as ligações rápidas à internet. Criaram-se assim condições materiais para dotar professores e alunos de ferramentas e meios tecnológicos para enfrentarem os desafios da educação em tempos de mudança, onde novos desafios emergiram.

\section{Integração das TIC}

A integração das tecnologias da Informação e comunicação no currículo são um reflexo da ação educativa de um país em todas as áreas desde a educação infantil ao secundário superior, os alunos são desde cedo iniciados na linguagem das novas tecnologias.

Nesta perspetiva, as tecnologias facilitam as atividades práticas de carácter interdisciplinar e transdisciplinar, permitem aos professores transformar radicalmente os seus modelos didáticos, permitem diversas disciplinas agruparem-se na realização de tarefas e projetos comuns . O uso das TIC “depende também, de uma forma muito direta, da preparação efetiva que os professores têm (ou não têm) para promoverem a sua inserção nas atividades escolares" (Costa, 2008. p.24). Os professores têm sido desafiados ao “ seu próprio desenvolvimento profissional, mas, sobretudo, para poderem utilizá-las com os seus alunos, proporcionando-lhes situações de aprendizagem inovadoras, mais interessantes e mais próximas da realidade envolvente” (Costa, 2003. p.1).

As TIC, não vai substituir a escola e o professor nem outros recursos didáticos, mas uma ferramenta nas mãos dos professores e alunos com critérios de oportunidade e eficácia. Elas são aceites na escola pelo poder de motivação pela sua versatilidade e suas possibilidades nos processos do ensino aprendizagem. As plataformas e-learning e a Web 2.0 são, atualmente, uma das ferramentas mais importantes desta evolução tecnológica, pois permitem práticas de ensino mais construtivas e interativas, que possibilitam o ensino a distância. Este tipo de práticas vem substituir os métodos de ensino tradicionais, incentivando o trabalho colaborativo e construtivo um espaço por excelência que permite a aplicação dessas novas abordagens educativas. O aluno melhora a sua aprendizagem pois explora livremente, faz perguntas quando necessita e repete quando não domina para passar à seguinte.

A Internet abre os olhos para horizontes distantes. A possibilidade da troca de experiências, as novas metodologias e a interação com outras culturas, estimulam a criação de muitos projetos voltados ao processo ensino aprendizagem. Segundo Moran (2006) "a Internet pode ajudar o professor a preparar melhor a sua aula, a ampliar as formas de lecionar, a modificar o processo de avaliação e de comunicação com o aluno e com os seus colegas." Corrobando com a perspetiva de Moran, podemos afirmar são inúmeras as potencialidades da internet apresenta.

Os recursos disponíveis na web são um grande centro de pesquisa para professores e alunos, abrangendo todas as áreas do conhecimento, considerando a imensa 
quantidade de informações e a extrema velocidade de retorno ao pesquisador.

No entanto, ao utilizar um recurso é importante que estejam bem definidos os objetivos que se querem atingir com a utilização do mesmo. Tomando como exemplo o computador, o facto de este ser utilizado, não quererá dizer que por si só, o computador, irá manter os alunos interessados durante a atividade, como afirma Leite, et al (2003: 8) “ a simples presença da tecnologia na sala de aula não garante qualidade nem dinamismo à prática pedagógica”. Seguindo ainda com o exemplo do computador, é necessário aproveitar o que este recurso provoca nos alunos, nomeadamente, o interesse, a atenção e a motivação. E, a partir daí, conduzir a atividade da melhor forma.

Para o desenvolvimento de diversos saberes e competências ao longo de todo o ensino básico as escolas devem garantir "no currículo dos alunos a possibilidade destes adquirirem uma capacidades significativa na utilização dos computadores e da Internet”(Freitas, 2007,p.23).

\section{Em torno do conceito de competências}

Segundo GEPE, o conceito de competência "move-se, entre duas perspectivas": uma de cariz behaviorista, outra de base sociocognitivista. Na primeira, define-se pela enumeração de comportamentos a observar; na segunda, a competência descreve o modo de realizar adequadamente uma ação, de responder a uma solicitação ou resolver um problema, numa situação concreta.

Várias são as definições e os sentidos do conceito de competência, as definições contêm variadas dimensões, as quais, por vezes, subentendem perspetivas teóricas diferentes. Para Leitão \& Alarcão (2006), uma definição possível é a veiculada pelo projeto DeSeCo (2002), que entende a competência como a capacidade de responder às exigências individuais ou sociais, ou de efetuar uma tarefa com sucesso, comportando dimensões cognitivas e não cognitivas. Pacheco (2011) apresenta três tipos de competência: cognitiva (saber), operacional (saber fazer) transversal (saber agir). Partindo desta diferenciação, consideramos que a competência cognitiva se situa no não observável e faz parte das regras da construção e uso do conhecimento. Por outro lado, a competência operacional centrando-se na transmissão e no saber-fazer. A competência transversal envolve uma série de operações cognitivas associadas tanto ao "aprender a aprender", como aos saberes procedimentais, nomeadamente, os métodos de trabalho, tratamento de informação, comunicação, relacionamento interpessoal e de grupo (Pacheco, 2011). Estas competências podem ser adquiridas quer por via formal, da formação académica, ou informal, pelos trajetos pessoais e profissionais e remetem para capacidades gerais, tais como, capacidade de antecipação, de iniciativa, de cooperação, de usar informação e comunicar, de trabalhar em equipa, que devem estar asseguradas para promoverem a flexibilidade profissional, independentemente do lugar onde os profissionais se encontram integrados.

A Comissão das Comunidades Europeias, define competencia digital do seguinte modo: "envolve a utilização segura e crítica das tecnologias da sociedade da informação para trabalho, tempos livres e comunicação. É sustentada pelas competências em TIC: o uso do computador para recuperar, avaliar, armazenar, produzir, apresentar e trocar informação e para comunicar e participar em redes de cooperação via Internet.” (2005, p.18).

De acordo com o disposto no Currículo Nacional do Ensino Básico, o uso das TIC em contexto educativo, para além de proporcionar o desenvolvimento de capacidades de pesquisa, organização e tratamento da informação é propício ao desenvolvimento de competências transversais no âmbito da cidadania, sugerindo-se por isso que as "experiências de aprendizagem educativas contemplem também a cooperação na partilha de informação, a apresentação dos resultados de pesquisa utilizando para o efeito, meios diversos, incluindo as novas tecnologias de informação e comunicação” (Currículo Nacional do Ensino Básico, 2001 p. 133).

\section{Método}

A metodologia propõe-se ajudar a compreender conduzir, todo o processo de investigação. O presente estudo de natureza exploratória descritiva (Coutinho, 2014). O caráter descritivo pretende descrever com exatidão os fatos e fenômenos de determinada realidade (Triviños,1987). A abordagem de natureza quantitativa quantifica as informações e possibilita a precisão dos resultados, evitando distorções de análise e de interpretação. A investigação quantitativa é centrada "na análise de factos e fenómenos observáveis e na medição/avaliação de variáveis comportamentais e/ou sócio afetivas, passíveis de serem medidas, comparadas e/ou relacionadas" (Coutinho, 2014, p. 24). A investigação quantitativa constitui um processo sistemático de recolha de dados observáveis e quantificáveis sobre um conjunto alargado de pessoas, relativos a um certo número de questões pré-determinadas.

Para identificar e contextualizar a utilização das TIC como recurso didático, para o desenvolvimento de competências transversais nos alunos, formulámos os seguintes objetivos: identificar as perceções dos alunos sobre as práticas TIC, implementadas pelos Professores; conhecer as potencialidades das TIC para o desenvolvimento de competências transversais nos alunos.

\section{Instrumentos de Recolha de Dados}

Como instrumento de recolha de dados utilizamos um inquérito por questionário (Moreira, 2006), (Ghiglione \& Matalon, 2001; Hill, M. \& Hill , A. 2009), elaborado com itens distribuídos pela escala de Likert.

Ghiglione e Matalon (2001) referem que o recurso ao inquérito por questionário faz-se, quando há a necessidade de compreender as atitudes, as opiniões, as preferências, as representações, etc., que só são acessíveis de uma forma prática pela linguagem e que só raramente se exprimem de forma espontânea. Acrescentam ainda que é através dele que podemos obter 
informações sobre o que se passa num determinado momento.

O questionário dos aluno era composto por 23 itens que passamos a descrever: i) uma nota introdutória, onde é feito o esclarecimento os objetivos do questionário e garantida a confidencialidade dos dados; ii) um bloco de questões respeitantes aos dados pessoais, constituído por 3 itens: idade, ano de escolaridade e sexo. iii) um segundo bloco constituído por 2 itens, (utilização das tic na sala de aula e a frequência; iv) um terceiro bloco do questionário com 9 itens; v) um quarto bloco com 7 itens; vi) e um último bloco do questionário com 3 itens.

Para responder aos objetivos da investigação, definimos quatro dimensões de análise: as carateristicas biográficas dos participntes; perceção sobre o funcionamento e dinâmicas escolares; Implementação das tic nas atividades letivas; aquisição de competências TIC; Nesta comunicação, apresentamos os dados relativos a duas dimensões: implementação das TIC nas atividades letivas; aquisição de competências TIC.

No tratamento dos dados utilizámos um programa informático, designado por SPSS 18 para Windows. A construção desta base de dados gerou a possibilidade de quantificar uma multiplicidade de dados e proceder a estatística descritiva.

\section{Amostra}

O estudo foi realizado num Agrupamento de Escolas, localizado na zona norte de Portugal, no ano letivo 2013/2014. Selecionámos uma amostra não probabilística para aplicarmos o inquérito por questionário, face à dimensão dos alunos do $2^{\circ}$ e $3^{\circ}$ ciclos do agrupamento, cuja população era constituída por 525 alunos, conseguimos uma amostragem que atinge cerca de $14,2 \%$ dessa população.

Assim, participaram no estudo $\mathrm{n}=75$ alunos , de quatro turmas $\left(5^{\circ}, 7^{\circ}, 8^{\circ}\right.$ e $9^{\circ}$ anos) com idades entre os 10 e 18 anos. A maioria dos participantes são do sexo feminino (52\%) e (48\%) são do sexo masculino. Quanto ao ano de escolaridade, $44 \%$ encontram-se no $7^{\circ}$ ano, $26,7 \%$ no $9^{\circ}$ ano e $20 \%$ no $8^{\circ}$ ano.

No que respeita à idade dos alunos, 50,6\% tem idades compreendidas entre os 12 e os 13 anos, enquanto 13,3\% têm idades entre os 16 e 18 anos.

A média de idade situa-se nos 12 e 13 anos
Tabela 1-Idade dos participantes

\begin{tabular}{lcc}
\hline & Frequência & Percentagem \\
\hline 10 anos & 4 & 5,3 \\
11 anos & 3 & 4,0 \\
12 anos & 19 & 25,3 \\
13 anos & 19 & 25,3 \\
14 anos & 14 & 18,7 \\
15 anos & 6 & 8,0 \\
16 anos & 3 & 4,0 \\
17 anos & 6 & 8,0 \\
18 anos & 1 & 1,3 \\
\hline Total & 75 & 100,0
\end{tabular}

\section{Resultados}

\section{Estatística descritiva Dimensão 1- Implementação das TIC nas atividades letivas}

Analisando os dados da primeira dimensão "a utilização das Tic na sala de aula”, os resultados evidenciam que elas fazem parte da vida quotidiana dos professores e alunos. Constatamos que 93,3\% dos inquiridos respondem quase sempre (4) e sempre (3). Verificámos uma unanimidade entre os inquiridos, pois a moda situa-se no ponto 4 (quase sempre) .

Os dados apontam que a média de utilização é de 3,57 e desvio padrão de ,619. Assim, os alunos referem que (67\%) dos professores utilizam quase sempre as tecnologias para promover atividades de pesquisa de informação, "proporcionando-lhes situações de aprendizagem inovadora” (Costa, 2003). O computador deixa de ser mero instrumento, uma máquina, e passa a ser um dispositivo pedagógico permitindo aos alunos e professores a partilha da informação em tempo real através de suportes tecnológicos para facilitar o processo ensino-aprendizagem.

Tabela 1. Perspetiva dos alunos sobre a utilização das TIC

\begin{tabular}{lrcc}
$\begin{array}{l}\text { Utilização } \\
\text { das tic }\end{array}$ & F & \% & Moda \\
\hline quase nunca & 5 & 6,7 & \\
sempre & 22 & 29,3 & \\
quase sempre & 48 & 64,0 & 4 \\
\hline Total & 75 & 100,0 &
\end{tabular}

Quanto à perspetiva dos alunos sobre as atividades realizadas na sala de aula, está descrita na tabela 2.

Realçamos os itens "Power Point”, e "visualização de vídeos” correspondendo a 58,7\% e 50,7\% das respostas s situam-se no quase sempre $(\mathrm{Q} / \mathrm{S})$. O valor da moda fica situado também no ponto $4(\mathrm{Q} / \mathrm{S})$. Constatamos que os itens "tabelas e gráficos” e “jogos didáticos” 37,3\% $42,7 \%$ situam-se no ponto 2 quase nunca $(\mathrm{Q} / \mathrm{N})$. A moda situa-se também no ponto 2.Verificamos que no item 
“quadro interativo” a percentagem de 33,3\% e a moda situa-se ponto 3 sempre (S).

Concluímos, assim, que os alunos utilizam as tecnologias na sala de aula, como apresentações de Power -Point seja em trabalho individual ou em trabalho de grupo, utilizam o quadro interativo e visualizando vídeos sobre temas do currículo. Salientamos a menor utilização no jogos didáticos e das tabelas e gráficos que em nosso entender deveria ser mais explorado por parte dos professores para a motivação dos alunos para determinados temas, tornando-os mais apelativos. Costa (2010, p.934) realça, a este respeito, que "não é o ensino das tecnologias o mais importante, mas sim, a aprendizagem com tecnologias”.

Tabela 2 . Tarefas realizadas na sala de aula

\begin{tabular}{|c|c|c|c|c|c|c|}
\hline \multicolumn{7}{|c|}{$\begin{array}{l}\text { Alunos } \mathrm{N}=75 \\
\mathrm{~F} / \% \text { de sujeitos }\end{array}$} \\
\hline $\begin{array}{l}\text { Atividades } \\
\text { sala de aula }\end{array}$ & & $\begin{array}{l}N \\
(1)\end{array}$ & $\begin{array}{l}\mathrm{Q} / \mathrm{N} \\
(2)\end{array}$ & $\begin{array}{c}\mathrm{S} \\
(3)\end{array}$ & $\begin{array}{l}\mathrm{Q} / \mathrm{S} \\
(4)\end{array}$ & $\begin{array}{c}\text { M } \\
\text { od } \\
\text { a }\end{array}$ \\
\hline \multirow[b]{2}{*}{ Power - Point } & $\mathrm{F}$ & 0 & 6 & 25 & 44 & \multirow[b]{2}{*}{4} \\
\hline & $\%$ & 0 & 8 & 33,3 & 58,7 & \\
\hline \multirow{2}{*}{$\begin{array}{l}\text { Quadro } \\
\text { interativo }\end{array}$} & $\mathrm{F}$ & 11 & 17 & 25 & 22 & \multirow[b]{2}{*}{3} \\
\hline & $\%$ & 14,7 & 22,7 & 33,3 & 29,3 & \\
\hline \multirow[b]{2}{*}{ Vídeos } & $\mathrm{F}$ & 1 & 25 & 11 & 38 & \multirow[b]{2}{*}{4} \\
\hline & $\%$ & 1,3 & 33,3 & 14,7 & 50,7 & \\
\hline \multirow[t]{2}{*}{ Jogos didáticos } & $\bar{F}$ & 22 & 28 & 8 & 17 & \multirow[b]{2}{*}{2} \\
\hline & $\%$ & 29,3 & 37,3 & 10,7 & 22,7 & \\
\hline \multirow[t]{2}{*}{ Tabelas/gráficos } & $\mathrm{F}$ & 20 & 32 & 7 & 16 & \multirow[b]{2}{*}{2} \\
\hline & $\%$ & 26,7 & 42,7 & 9,3 & 21,3 & \\
\hline
\end{tabular}

A perceção dos alunos sobre as tarefas realizadas fora do contexto da sala de aula. Constatamos na tabela 3, que o item "Plataforma moodle", 40\% dos inquiridos referem $(\mathrm{Q} / \mathrm{N})$ e $33,3 \%$ refere $(\mathrm{N})$ utilizam esta ferramenta online de apoio às aprendizagens que permite ao professor orientar o trabalho dos alunos, com informações, sumários, fichas de trabalho, hiperligações para conteúdos, possibilidade de submissão e organização de trabalhos, ou seja, estratégia para incrementar a motivação e autonomia dos alunos. Estes dados evidenciam que apenas 26,6\% dos alunos utilizam esta ferramenta online. Pela observação da tabela 3 , verificamos que as respostas dos alunos manifestaram interesse/recetividade no item "pesquisa e redes sociais" este situa-se nos $41,3 \%(\mathrm{Q} / \mathrm{S})$, a moda situa.se no ponto 4 . Os alunos aderem a atividades que não necessitam de grande intervenção por parte do professor, permitindo ao aluno controlar a sua própria aprendizagem. No ítem "email” ou correio eletrónico, verificamos que o (N) e o (S) mantem a mesma percentagem $18,7 \%$ e $37,3(\mathrm{Q} / \mathrm{N})$ totalizando $56 \%$, é relevante a baixa utilização do correio eletrónico pelos alunos. Quanto ao ítem "publicar trabalhos na página da escola ou no jornal escolar " $46,7 \%$ refere que $(\mathrm{N})$ a moda situa-se no ponto $1(\mathrm{~N})$.

Estes resultados indicam que os alunos têm um grau elevado de confiança na utilização da Pesquisa/redes sociais e um grau de confiança baixo relativamente a "Uso do email”, da plataforma moodle e na publicação de trabalhos.
Tabela 3. Tarefas realizadas fora do espaço na sala de aula

\begin{tabular}{|c|c|c|c|c|c|c|}
\hline \multicolumn{7}{|c|}{$\begin{array}{c}\text { Alunos } \mathrm{N}=75 \\
\% \text { de sujeitos }\end{array}$} \\
\hline \multicolumn{2}{|l|}{$\begin{array}{c}\text { Atividades } \\
\text { fora do espaço } \\
\text { aula }\end{array}$} & $\begin{array}{c}\mathrm{N} \\
(1)\end{array}$ & $\begin{array}{l}\mathrm{Q} / \mathrm{N} \\
(2)\end{array}$ & $\begin{array}{c}\text { S } \\
(3)\end{array}$ & $\begin{array}{l}\mathrm{Q} / \mathrm{S} \\
(4)\end{array}$ & Moda \\
\hline \multirow{2}{*}{$\begin{array}{l}\text { Plataforma } \\
\text { moodle }\end{array}$} & $\mathrm{F}$ & 25 & 30 & 6 & 14 & \\
\hline & $\%$ & 33,3 & 40 & 8 & 18,6 & 2 \\
\hline \multirow{2}{*}{$\begin{array}{l}\text { Pesquisa/redes } \\
\text { sociais }\end{array}$} & $F$ & 2 & 14 & 28 & 31 & \\
\hline & $\%$ & 2,7 & 18,7 & 37,3 & 41,3 & 4 \\
\hline \multirow[t]{2}{*}{ e-mail } & $\mathrm{F}$ & 14 & 28 & 14 & 19 & \\
\hline & $\%$ & 18,7 & 37,3 & 18,7 & 25,3 & 2 \\
\hline \multirow{2}{*}{$\begin{array}{l}\text { Publicar/trabalh } \\
\text { os/jornal escolar }\end{array}$} & $\mathrm{F}$ & 35 & 27 & 2 & 11 & \\
\hline & $\%$ & 46,7 & 36 & 2,7 & 14,7 & 1 \\
\hline
\end{tabular}

O estudo também procurou saber junto dos alunos quais os locais da escola onde acediam aos computadores e à internet.

Os alunos referem que acedem o computador na sala de aula $48 \%(\mathrm{Q} / \mathrm{S})$ moda 4 , na sala de informática $48 \%$ $(\mathrm{Q} / \mathrm{S})$ moda 4 e 41,3\% (Q/S) moda 4 na biblioteca. Tendo em conta estes dados podemos salientar através do valor da moda, situada no ponto 4 que houve unanimidade entre os inquiridos sobre locais da escola onde acediam aos computadores e à internet.

\section{Estatística descritiva Dimensão 2- Aquisição de competências}

Relativamente aos itens da tabela 4, procedemos também ao cálculo das médias aritméticas das respostas e respetivos valores do desvio-padrão.

Esta medida de dispersão ou seja "O valor do desvio-padrão nível de consenso 0,00 a 0,29 consenso alto, 0,30 a 0,59 consenso moderado/alto, 0,60 a 0,89 consenso moderado/baixo e mais de 0,90 consenso baixo, (Morgado, 2003, p. 351).

Analisando a tabela 4, e de acordo com os itens do questionário, constatamos que $48 \%$ dos alunos concorda (C) no "grau de confiança na utilização do computador " e 52 \% dos alunos concorda (C) no "grau de confiança na utilização da internet”, situa-se a média $=3,28$, e $\mathrm{DP}=0,669$, embora com um consenso moderado baixo. ).Nos itens "computador ferramenta de aprendizagem” e “ a pesquisa na internet influência positivamente a minha aprendizagem" os inquiridos manifestam opiniões positiva, correspondendo a 54,7\% e $46,7 \%$, concordo totalmente $(\mathrm{C} / \mathrm{T})$.

No item "sinto-me confiante adquirir novas competências de utilização Tic”, 46\% refere (C/T) e $41,3 \%$ (C), totalizando 87,3\%, verificamos uma média $(3,35)$ e $(\mathrm{DP}=, 707)$ manifestando tendencia positiva. Estes resultados indicam que os alunos sentem-se confiantes em adquirir competências na utilização das TIC, indispensáveis à aprendizagem, desenvolvem a capacidades de pesquisa numa perspetiva de aprender a aprender, onde valorizando a autonomia e o espirito critico perante a utilização dos equipamentos tecnológicos e da Internet, como são os casos de pesquisas / redes sociais, digitar um texto ou produzir uma apresentação simples. Por outro lado, a surpresa é o pouco à vontade denotam quando colocados perante situações de modalidades de trabalhar com o correio 
electrónico, trabalhar na plataforma moodle, jogos didáticos, onde revelaram um grau de confiança fraco ou mesmo muito fraco nas suas competências.

\begin{tabular}{|c|c|c|c|c|c|c|c|}
\hline \multicolumn{8}{|c|}{$\begin{array}{c}\text { Alunos } \mathrm{N}=75 \\
\% \text { de sujeitos }\end{array}$} \\
\hline G/confiança. & & $\begin{array}{l}\mathrm{N} / \mathrm{C} \\
(1)\end{array}$ & $\begin{array}{l}\mathrm{C} / \\
\mathrm{P} \\
(2)\end{array}$ & $\begin{array}{l}\text { C } \\
\text { (3) }\end{array}$ & $\begin{array}{l}\mathrm{C} / \mathrm{T} \\
(4)\end{array}$ & M & $\mathrm{D} / \mathrm{P}$ \\
\hline \multirow{3}{*}{$\begin{array}{l}\text { A utilizar } 0 \\
\text { computador. }\end{array}$} & & 0 & 9 & 36 & 30 & \multirow{3}{*}{3,28} & \multirow{3}{*}{,669 } \\
\hline & o & & & & & & \\
\hline & & 0 & 12 & 48 & 40 & & \\
\hline \multirow{2}{*}{$\begin{array}{l}\text { A utilizar a } \\
\text { internet. }\end{array}$} & & 1 & 6 & 39 & 29 & \multirow[b]{2}{*}{3,28} & \multirow[b]{2}{*}{,669 } \\
\hline & $\%$ & 1,3 & 8 & 52 & 38,7 & & \\
\hline \multirow{2}{*}{$\begin{array}{l}\text { Computador } \\
\text { ferramenta de } \\
\text { aprendizagem. }\end{array}$} & & 0 & 5 & 29 & 41 & \multirow[b]{2}{*}{3,48} & \multirow[b]{2}{*}{,623 } \\
\hline & $\%$ & 0 & 6,7 & 38,7 & 54,7 & & \\
\hline \multirow{2}{*}{$\begin{array}{l}\text { A pesquisa na } \\
\text { internet } \\
\text { influencia a } \\
\text { aprendizagem }\end{array}$} & & 1 & 7 & 32 & 35 & \multirow[t]{2}{*}{3,19} & \multirow[t]{2}{*}{,800 } \\
\hline & $\%$ & 1,3 & 9,3 & 42,7 & 46,7 & & \\
\hline \multirow{3}{*}{$\begin{array}{l}\text { Internet facilita } \\
\text { a comunicação }\end{array}$} & & 3 & 9 & 33 & 30 & \multirow{3}{*}{3,32} & \multirow{3}{*}{,756 } \\
\hline & o & & & & & & \\
\hline & & 4 & 12 & 44 & 40 & & \\
\hline \multirow{2}{*}{$\begin{array}{l}\text { adquirir } \\
\text { competências de } \\
\text { utilização. }\end{array}$} & & 2 & 7 & 31 & 35 & \multirow[b]{2}{*}{3,35} & \multirow[b]{2}{*}{,707 } \\
\hline & & 2,7 & 9,3 & 41,3 & 46,7 & & \\
\hline
\end{tabular}

Corrobando com um estudo efetuado por Castro (2006) no qual pretendeu analisar a influência das TIC no desenvolvimento do currículo por competências. Constatou que as TIC provoca efeitos no desenvolvimento de competências de pesquisa, recolha, seleção, ordenação, gestão e utilização da informação, como aqui inferimos.

\section{Conclusão}

As TIC são um veículo para a promoção do ensino-aprendizagem quando integradas nas práticas letivas dos professores, são portadoras de oportunidades capazes de favorecer as aprendizagens dos alunos. O Plano Tecnológico da Educação (PTE) apetrechou as escolas do 2. ${ }^{\circ}$ e $3 .^{\circ}$ ciclos com computadores, videoprojectores e internet de banda larga de alta velocidade, entre outros equipamentos e levou a internet a todas as salas através de pontos de acesso com e sem fios. A utilização e generalização dos computadores e o acesso às redes eletrónicas por parte dos alunos e professores, proporcionam experiências de aprendizagem de acesso à informação e constituem assim, uma base para desenvolver rotinas de manipulação, de experimentação e de resolução de problemas. No entanto, não podemos esquecer é necessário que os professores e os alunos disponibilizem tempo suficiente para a utilização e exploração das potencialidades das ferramentas e, ao mesmo tempo, desenvolvam competências que permitam ter a confiança necessária na sua utilização.

Os resultados deste estudo apontam o uso do computador como um dos recursos utilizados para o desenvolvimento de competências, ao longo da escolaridade, a maioria dos alunos acede, organiza e sistematiza a informação em formato digital (pesquisa, seleciona ), comunica com os outros, individualmente ou em grupo, de forma síncrona e/ou assíncrona. A utilização das tecnologias nas atividades letivas, é, hoje, inquestionável por parte dos professores e alunos é uma resposta necessária aos permanentes desafios de inovação e da mudança. Podemos concluir do estudo que os professores utilizam as TIC na sala de aula (quadro interativo), redimensionando-a uma relação tripartida. Os alunos acedem na biblioteca, na sala de informática e nas salas de aulas e utilizam-nas de forma mais diversificada.

Os resultados revelam que a aceitação desta "ferramenta", como fazendo parte integrante processo do ensino-aprendizagem, assegura um percurso coerente de formação e a aquisição de um conjunto de competências. As tecnologias já transformaram a relação tradicional professor aluno, redimensionando-a numa relação tripartida.

\section{Referências}

Alarcão, I. \& Leitão, A. (2006) Revista Portuguesa de Educação, 19(2), pp. 51-84 CIEd - Universidade do Minho

Almeida, M. \& Moran, J. (Org.)(2005). Integração das Tecnologias na Educação. Brasília:Ministério da Educação. Secretaria de Educação a Distância.

Castells, M. (2005). A Sociedade em Rede. A Era da Informação: Economia, Sociedade e Cultura (2. ed.,Vol.1). Lisboa: Fundação Calouste Gulbenkian

Castells, M. (2013). O poder da comunicação. Lisboa: Fundação Calouste Gulbenkian.

Castro, C. (2006). A Influência das Tecnologias de Informação e Comunicação (TIC) no desenvolvimento do currículo por competências. Dissertação de Mestrado. Braga:IEP-UM

Costa, F. (2003). Ensinar e aprender com tecnologias na Formação Inicial de Professores. In A. Estrela \& J. Ferreira 8 (eds.). A Formação de professores à luz da investigação,Livros de Actas do XII Colóquio da AFIRSE,( pp.751-763). Lisboa: Afirse.

COSTA, F. (coord.) (2008). Competências TIC, estudo de implementação (Vol. 1). Lisboa: Gabinete de Estatística e Planeamento da Educação (GEPE).

Costa, F. (2010). Metas de Aprendizagem na área das TIC: Aprender com Tecnologias. In Actas do I Encontro Internacional TIC e Educação 2010. Lisboa: Instituto Superior de Educação, 931-936.

Coutinho, C. (2014). Metodologia de investigação em ciências sociais e humanas: Teoria e prática. Lisboa: Almedina.

D.E.B. (2001a). Reorganização curricular do Ensino Básico: princípios, medidas e implicações. Lisboa: Ministério da Educação.

D.E.B. (2001b). Currículo Nacional do Ensino Básico: competências essenciais. Lisboa: Ministério da Educação 
Ghiglione, R. \& Matalon, B. (2001). O Inquérito. Teoria e Prática. Oeiras: Celta Editora.

Morgado, J. (2003). Processos e práticas de (re)construção da autonomia curricular. Tese de Doutoramento. Braga: Universidade do Minho.

Pacheco, J. (2011). Discursos e lugares das competências em contexto de educação e formação.

Porto:

Porto

Editora.
Ministério, E (2008). Plano Tecnológico da Educação Resolução do Conselho de Ministros n. ${ }^{\circ}$ 137/2007.Lisboa: Ministério da Educação. Consultado em 20 de abril de 2012, disponível em http://www.planotecnologico.pt/document/OPlanoT ecnologico.pdf 